\title{
Enantioselective dioxytosylation of styrenes using lactate- based chiral hypervalent iodine(III)
}

\author{
Morifumi Fujita*, Koki Miura and Takashi Sugimura
}

\author{
Letter \\ Address: \\ Graduate School of Material Science, University of Hyogo, Kohto, \\ Kamigori, Hyogo 678-1297, Japan \\ Email: \\ Morifumi Fujita* - fuji@sci.u-hyogo.ac.jp \\ * Corresponding author \\ Keywords: \\ 1,2-difunctionalization of alkenes; enantioselective synthesis; \\ hypervalent iodine; oxidation
}

Beilstein J. Org. Chem. 2018, 14, 659-663. doi:10.3762/bjoc. 14.53

Received: 25 December 2017

Accepted: 06 March 2018

Published: 20 March 2018

This article is part of the Thematic Series "Hypervalent iodine chemistry in organic synthesis".

Guest Editor: T. Wirth

(C) 2018 Fujita et al.; licensee Beilstein-Institut.

License and terms: see end of document.

\begin{abstract}
A series of optically active hypervalent iodine(III) reagents prepared from the corresponding (R)-2-(2-iodophenoxy)propanoate derivative was employed for the asymmetric dioxytosylation of styrene and its derivatives. The electrophilic addition of the hypervalent iodine(III) compound toward styrene proceeded with high enantioface selectivity to give 1-aryl-1,2-di(tosyloxy)ethane with an enantiomeric excess of $70-96 \%$ of the $(S)$-isomer.
\end{abstract}

\section{Findings}

Hypervalent aryl- $\lambda^{3}$-iodanes have been widely used for metalfree oxidation with high selectivity in organic synthesis [1-3]. The reactivity of an aryl- $\lambda^{3}$-iodane is controlled by the electronic and steric properties of the aryl group and the heteroatomic ligand coordinated to the iodine atom. Optically active hypervalent iodine compounds contain chiral ligands or chiral aryl groups. Several types of optically active hypervalent iodine reagents and catalysts have been developed for highly stereocontrolled oxidative transformations [4-14]. The enantioselective vicinal difunctionalization of alkenes constitutes one type of attractive transformation achieved by chiral hypervalent iodine compounds. As a seminal example in this field, Wirth et al. [15-17] reported the dioxytosylation of styrene (1a, Scheme 1). Chiral hypervalent iodine reagents 2 bearing a 1-methoxyethyl side chain were used for enantiocontrol of the dioxytosylation, and the maximum enantiomeric excess (ee) of the product 3a reached $65 \%$. Despite recent rapid progress in the field of asymmetric oxidation achieved by chiral hypervalent iodine compounds, there has been no subsequent examination of dioxytosylation, which can be used as a standard reaction for comparing the enantiocontrolling ability of chiral hypervalent iodine reagents. 


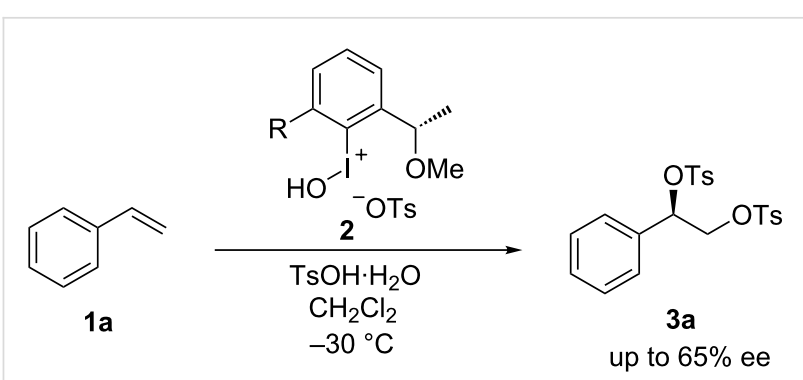

Scheme 1: Enantioselective dioxytosylation of styrene as a seminal example.

The design of chiral hypervalent iodine reagents using a lactate motif has been employed for several types of oxidation reaction since we first reported this procedure [18]. Enantioselective oxidative transformations include the dearomatization of phenols [19-24], $\alpha$-functionalization of carbonyl compounds [25-29], and vicinal difunctionalization of alkenes [18,30-50]. Here, the efficiency of the lactate-based chiral hypervalent iodine reagents $\mathbf{4 a - e}$ (Figure 1) was assessed using the dioxytosylation of styrenes as a reference reaction.

A series of lactate-derived aryl- $\lambda^{3}$-iodanes $4 \mathbf{a}-\mathbf{e}$ was used for the oxidation of styrenes $\mathbf{1}$ in the presence of $p$-toluenesulfonic acid $(\mathrm{TsOH})$ in dichloromethane. The reaction proceeded at $-50{ }^{\circ} \mathrm{C}$ to give the 1,2-dioxytosylated product 3 and the rearranged product 5 . The yields of $\mathbf{3}$ and $\mathbf{5}$ were determined by ${ }^{1} \mathrm{H}$ NMR using an internal standard. The ee of $\mathbf{3}$ was determined by chiral HPLC analysis. The results for the yields and ee are summarized in Table 1.

The reaction of styrene (1a) with $\mathbf{4 a}$ gave the 1,2-dioxytosylated product 3a with $70 \%$ ee of the $(S)$-isomer (Table 1, entry 1). An ee of equal to or greater than $70 \%$ was also achieved in the reactions with the other lactate-based reagents $4 \mathbf{b}-\mathbf{e}$ (Table 1, entries 2-5). The reaction with the 2,6-bis(lactate)aryl reagent $4 \mathbf{e}$ provided a high ee of $92 \%$. The reactions of $p$-chlorostyrene (1b) gave $\mathbf{3 b}$ with a similar ee, and the ratios of $\mathbf{3}$ to $\mathbf{5}(\mathbf{3 b}$ to $\mathbf{5 b})$ were higher than those in the reaction of $\mathbf{1 a}$
(Table 1, entries 6-8). In the reactions of $o$-methylstyrene (1c), the ee of the 1,2-dioxytosylated product $3 \mathbf{c}$ was slightly higher than those of $\mathbf{3 a}$ and $\mathbf{3 b}$, but the regioselectivity for $\mathbf{3} \mathbf{c}$ over $\mathbf{5 c}$ was poor (Table 1, entries 9 and 10).

Scheme 2 illustrates possible reaction pathways that lead to 3 and the achiral byproduct 5 . The treatment of (diacetoxyiodo)benzene with $\mathrm{TsOH}$ readily gives Koser's reagent $[\mathrm{PhI}(\mathrm{OH}) \mathrm{OTs}]$ [51], which has a higher electrophilicity toward the carbon-carbon double bond in $\mathbf{1}$. The dioxytosylation of alkenes with Koser's reagent was found to proceed via an $\mathrm{S}_{\mathrm{N}} 2$ reaction of a cyclic intermediate such as $\mathbf{I}_{\mathbf{1}}$, judging from the syn selectivity of the dioxytosylation [52,53]. The attack of the tosylate ion on $\mathbf{I}_{\mathbf{1}}$ possibly takes place at the benzylic position or at the methylene carbon atom. The positive charge of $\mathbf{I}_{\mathbf{1}}$ may be stabilized by the aryl group and localized at the benzylic position. This may allow the preferential formation of $\mathbf{I}_{\mathbf{3}}$ from $\mathbf{I}_{\mathbf{1}}$. If $\mathbf{I}_{\mathbf{2}}$ was the major intermediate in the pathway leading to $\mathbf{3}$, the stereochemical purity of $\mathbf{3}$ would have decreased owing to the facile elimination of the iodonium group [54] at the benzylic position of $\mathbf{I}_{2}\left(\mathrm{~S}_{\mathrm{N}} 1\right)$. The high enantiomeric ratio of $\mathbf{3}$ can be rationalized via a preference for the $\mathbf{I}_{\mathbf{1}} \rightarrow \mathbf{I}_{\mathbf{3}} \rightarrow \mathbf{3}$ pathway over the $\mathbf{I}_{\mathbf{1}} \rightarrow \mathbf{I}_{\mathbf{2}} \rightarrow \mathbf{3}$ pathway. The product ratio of $\mathbf{3}$ to 5 was affected by the ring substituent in styrenes 1: the electron-withdrawing chloro substituent in $\mathbf{1 b}$ increased the amount of $\mathbf{3}$, whereas the electron-donating methyl substituent in $\mathbf{1 c}$ decreased the amount of $\mathbf{3}$. An electron-donating aryl group increases the rate of participation of the aryl group $\left(\mathbf{I}_{3} \rightarrow \mathbf{I}_{4}\right)$. In other words, a reaction pathway that bifurcates from $\mathbf{I}_{3}$ to $\mathbf{3}$ and $\mathbf{5}$ agrees well with the regioselectivity for $\mathbf{3}$ over $\mathbf{5}$ observed for the substituted styrenes. The phenonium cation intermediate $\mathbf{I}_{\mathbf{4}}$ contains two reaction sites on the ethylene bridge. Electron donation due to the lone pair on the oxygen atom of the internal tosyloxy group may weaken the bond between the tosyloxybonded carbon and the quaternary carbon in $\mathbf{I}_{\mathbf{4}}$.

The reaction of styrene with $\mathbf{4 a}-\mathbf{e}$ preferentially gave $(S)-\mathbf{3}$, which forms via an electrophilic addition of the iodane toward the $S i$ face of styrene, followed by an $\mathrm{S}_{\mathrm{N}} 2$ reaction with the<smiles>[R]C(=O)O[C@H](C)C(=O)O[C@H](C)C(=O)OC</smiles> 
Table 1: Enantioselective dioxytosylation of styrenes 1 using aryl- $\lambda^{3}$-iodanes $4 .^{a}$

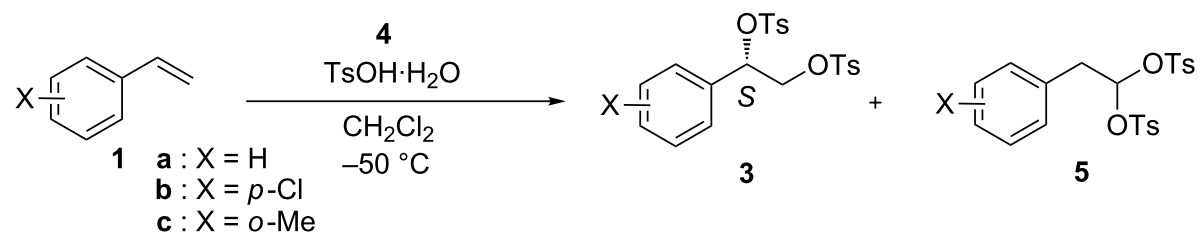

\begin{tabular}{|c|c|c|c|c|c|}
\hline \multirow[b]{2}{*}{ Entry } & \multirow[b]{2}{*}{ Substrate } & \multirow[b]{2}{*}{ Reagent } & \multicolumn{2}{|c|}{ Yield $(\%)^{b}$} & \multirow[b]{2}{*}{ ee of $3(\%)^{c, d}$} \\
\hline & & & 3 & 5 & \\
\hline 1 & $1 \mathbf{a}(X=H)$ & $4 a$ & 53 & 15 & $70(S)$ \\
\hline 2 & $1 \mathbf{a}(X=H)$ & $4 b$ & 49 & 16 & $80(S)$ \\
\hline 3 & 1a $(X=H)$ & $4 c$ & 41 & 14 & $78(S)$ \\
\hline 4 & $1 \mathbf{a}(X=H)$ & $4 d$ & 41 & 22 & $70(S)$ \\
\hline 5 & $1 \mathbf{a}(X=H)$ & $4 e$ & 80 & 20 & $92(S)$ \\
\hline 6 & $\mathbf{1 b}(\mathrm{X}=p-\mathrm{Cl})^{\mathrm{e}}$ & $4 a$ & 63 & 6 & 70 \\
\hline 7 & $\mathbf{1 b}(\mathrm{X}=p-\mathrm{Cl})^{\mathrm{e}}$ & $4 b$ & 46 & 5 & 76 \\
\hline 8 & 1b $(\mathrm{X}=p-\mathrm{Cl})^{\mathrm{e}}$ & $4 e$ & 79 & 5 & 90 \\
\hline 9 & $1 \mathrm{c}(\mathrm{X}=\mathrm{o}-\mathrm{Me})$ & $4 a$ & 7 & 34 & 79 \\
\hline 10 & $1 \mathrm{c}(\mathrm{X}=\mathrm{o}-\mathrm{Me})$ & $4 e$ & 10 & 35 & 96 \\
\hline
\end{tabular}

aThe reaction was carried out at $-50^{\circ} \mathrm{C}$ in dichloromethane containing $4(47 \mathrm{mM})$, TsOH $(86 \mathrm{mM})$, and 1 (43 mM) for $4 \mathrm{~h}$. b The yield was determined by ${ }^{1} \mathrm{H}$ NMR using an internal standard. ${ }^{\circ}$ The ee was determined by chiral HPLC using a Daicel CHIRALPAK AD column $(\varnothing 4.6 \mathrm{~mm} \times 250 \mathrm{~mm})$.

dPreferential configuration of product $\mathbf{3}$. The absolute stereochemistry of $\mathbf{3 b}$ and $\mathbf{3 c}$ was not determined. ${ }^{\mathrm{e}}$ The reaction was carried out for $20 \mathrm{~h}$.

tosylate ion. If an $\mathrm{S}_{\mathrm{N}} 1$ mechanism were involved in the oxytosylation of $\mathbf{I}_{\mathbf{1}}$, the enantiomeric ratio of $\mathbf{3}$ would decrease owing to the planar structure of the benzylic cation. Thus, the tosylate ion may act as an effective nucleophile for the $\mathrm{S}_{\mathrm{N}} 2$ reaction of $\mathbf{I}_{1}$. The stereoface-differentiation in the dioxytosylation reaction using the lactate-derived aryl- $\lambda^{3}$-iodanes is similar to that in preceding reactions [14], which include the diacetoxylation $[38,39,50]$ and diamination $[30,49]$ of styrene.

In summary, the reaction of styrenes with lactate-derived aryl$\lambda^{3}$-iodanes gave the dioxytosylated product with an ee of $70-96 \%$.

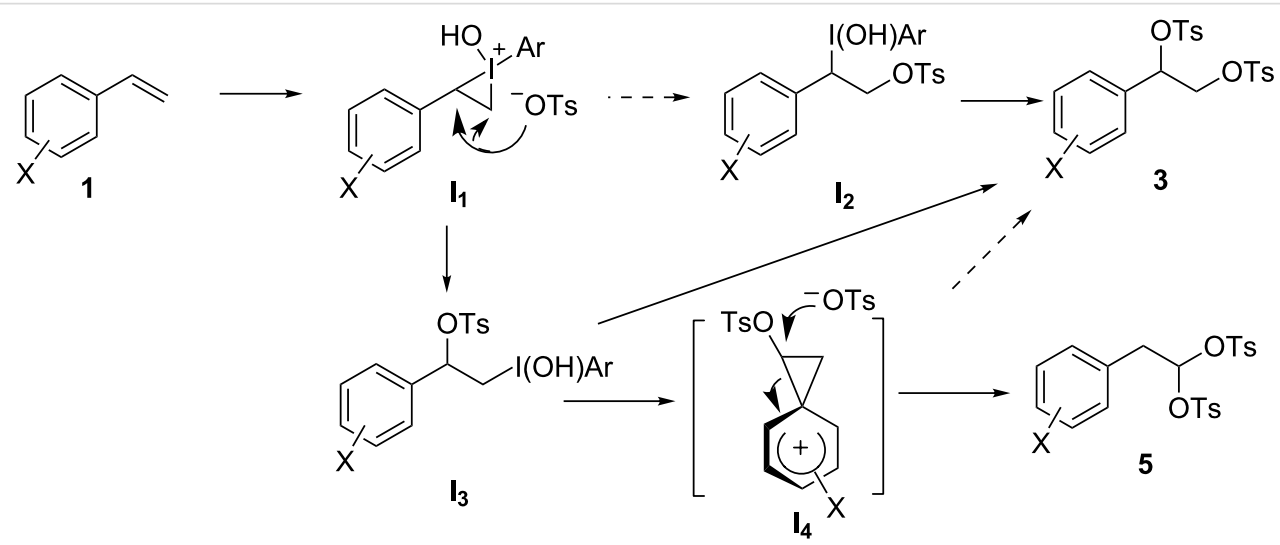

Scheme 2: Plausible pathways in dioxytosylation of styrenes. 


\section{Supporting Information}

\section{Supporting Information File 1}

Experimental procedures, characterization data, and copies of ${ }^{1} \mathrm{H}$ and ${ }^{13} \mathrm{C}$ NMR spectra are available.

[https://www.beilstein-journals.org/bjoc/content/ supplementary/1860-5397-14-53-S1.pdf]

\section{Acknowledgements}

Financial support from University of Hyogo is gratefully acknowledged.

\section{ORCID ${ }^{\circledR} \mathrm{iDs}$}

Morifumi Fujita - https://orcid.org/0000-0003-1006-1416

\section{References}

1. Zhdankin, V. V. Hypervalent lodine Chemistry; John Wiley \& Sons: Chichester, U.K., 2014.

2. Yoshimura, A.; Zhdankin, V. V. Chem. Rev. 2016, 116, 3328-3435. doi:10.1021/acs.chemrev.5b00547

3. Wirth, T., Ed. Hypervalent lodine Chemistry; Springer: Basel, Switzerland, 2016. doi:10.1007/978-3-319-33733-3

4. Ngatimin, M.; Lupton, D. W. Aust. J. Chem. 2010, 63, 653-658. doi:10.1071/CH09625

5. Liang, H.; Ciufolini, M. A. Angew. Chem., Int. Ed. 2011, 50, 11849-11851. doi:10.1002/anie.201106127 Angew. Chem. 2011, 123, 12051-12053. doi:10.1002/ange.201106127

6. Uyanik, M.; Ishihara, K. J. Synth. Org. Chem., Jpn. 2012, 70, 1116-1122. doi:10.5059/yukigoseikyokaishi.70.1116

7. Parra, A.; Reboredo, S. Chem. - Eur. J. 2013, 19, 17244-17260. doi:10.1002/chem.201302220

8. Singh, F. V.; Wirth, T. Chem. - Asian J. 2014, 9, 950-971. doi:10.1002/asia.201301582

9. Romero, R. M.; Wöste, T. H.; Muñiz, K. Chem. - Asian J. 2014, 9, 972-983. doi:10.1002/asia.201301637

10. Harned, A. M. Tetrahedron Lett. 2014, 55, 4681-4689. doi:10.1016/j.tetlet.2014.06.051

11. Zheng, Z. S.; Zhang-Negrerie, D.; Du, Y. F.; Zhao, K. Sci. China: Chem. 2014, 57, 189-214. doi:10.1007/s11426-013-5043-1

12. Berthiol, F. Synthesis 2015, 47, 587-603. doi:10.1055/s-0034-1379892

13. Basdevant, B.; Guilbault, A.-A.; Beaulieu, S.; Lauriers, A. J.-D.; Legault, C. Y. Pure Appl. Chem. 2017, 89, 781-789. doi:10.1515/pac-2016-1212

14. Fujita, M. Tetrahedron Lett. 2017, 58, 4409-4419. doi:10.1016/j.tetlet.2017.10.019

15. Wirth, T.; Hirt, U. H. Tetrahedron: Asymmetry 1997, 8, 23-26. doi:10.1016/S0957-4166(96)00469-7

16. Hirt, U. H.; Spingler, B.; Wirth, T. J. Org. Chem. 1998, 63, 7674-7679. doi:10.1021/jo980475x

17. Hirt, U. H.; Schuster, M. F. H.; French, A. N.; Wiest, O. G.; Wirth, T. Eur. J. Org. Chem. 2001, 1569-1579. doi:10.1002/1099-0690(200104)2001:8<1569::AID-EJOC1569>3.0.CO ;2-T

18. Fujita, M.; Okuno, S.; Lee, H. J.; Sugimura, T.; Okuyama, T. Tetrahedron Lett. 2007, 48, 8691-8694. doi:10.1016/j.tetlet.2007.10.015
19. Uyanik, M.; Yasui, T.; Ishihara, K. Angew. Chem., Int. Ed. 2010, 49, 2175-2177. doi:10.1002/anie.200907352 Angew. Chem. 2010, 122, 2221-2223. doi:10.1002/ange.200907352

20. Uyanik, M.; Yasui, T.; Ishihara, K. Angew. Chem., Int. Ed. 2013, 52, 9215-9218. doi:10.1002/anie.201303559 Angew. Chem. 2013, 125, 9385-9388. doi:10.1002/ange.201303559

21. Zhang, D.-Y.; Xu, L.; Wu, H.; Gong, L.-Z. Chem. - Eur. J. 2015, 21 , 10314-10317. doi:10.1002/chem.201501583

22. Yoshida, Y.; Magara, A.; Mino, T.; Sakamoto, M. Tetrahedron Lett. 2016, 57, 5103-5107. doi:10.1016/j.tetlet.2016.10.016

23. Uyanik, M.; Sasakura, N.; Mizuno, M.; Ishihara, K. ACS Catal. 2017, 7, 872-876. doi:10.1021/acscatal.6b03380

24. Jain, N.; Xu, S.; Ciufolini, M. A. Chem. - Eur. J. 2017, 23, 4542-4546. doi:10.1002/chem.201700667

25. Mizar, P.; Wirth, T. Angew. Chem., Int. Ed. 2014, 53, 5993-5997. doi:10.1002/anie.201400405 Angew. Chem. 2014, 126, 6103-6107. doi:10.1002/ange.201400405

26. Wu, H.; He, Y.-P.; Xu, L.; Zhang, D.-Y.; Gong, L.-Z. Angew. Chem., Int. Ed. 2014, 53, 3466-3469. doi:10.1002/anie.201309967 Angew. Chem. 2014, 126, 3534-3537. doi:10.1002/ange.201309967

27. Basdevant, B.; Legault, C. Y. Org. Lett. 2015, 17, 4918-4921. doi:10.1021/acs.orglett.5b02501

28. Feng, Y.; Huang, R.; Hu, L.; Xiong, Y.; Coeffard, V. Synthesis 2016, 48, 2637-2644. doi:10.1055/s-0035-1561442

29. Cao, Y.; Zhang, X.; Lin, G.; Zhang-Negrerie, D.; Du, Y. Org. Lett. 2016, 18, 5580-5583. doi:10.1021/acs.orglett.6b02816

30. Muñiz, K.; Barreiro, L.; Romero, R. M.; Martínez, C. J. Am. Chem. Soc. 2017, 139, 4354-4357. doi:10.1021/jacs.7b01443

31. Gelis, C.; Dumoulin, A.; Bekkaye, M.; Neuville, L.; Masson, G. Org. Lett. 2017, 19, 278-281. doi:10.1021/acs.orglett.6b03631

32. Qurban, J.; Elsherbini, M.; Wirth, T. J. Org. Chem. 2017, 82, 11872-11876. doi:10.1021/acs.joc.7b01571

33. Shimogaki, M.; Fujita, M.; Sugimura, T. J. Org. Chem. 2017, 82, 11836-11840. doi:10.1021/acs.joc.7b01141

34. Banik, S. M.; Medley, J. W.; Jacobsen, E. N. Science 2016, 353, 51-54. doi:10.1126/science.aaf8078

35. Banik, S. M.; Medley, J. W.; Jacobsen, E. N. J. Am. Chem. Soc. 2016, 138, 5000-5003. doi:10.1021/jacs.6b02391

36. Woerly, E.; Banik, S. M.; Jacobsen, E. N. J. Am. Chem. Soc. 2016, 138, 13858-13861. doi:10.1021/jacs.6b09499

37. Ahmad, A.; Silva, L. F., Jr. J. Org. Chem. 2016, 81, 2174-2181. doi:10.1021/acs.joc.5b02803

38. Haubenreisser, S.; Wöste, T. H.; Martínez, C.; Ishihara, K.; Muñiz, K. Angew. Chem., Int. Ed. 2016, 55, 413-417. doi:10.1002/anie.201507180 Angew. Chem. 2016, 128, 422-426. doi:10.1002/ange.201507180

39. Wöste, T. H.; Muñiz, K. Synthesis 2016, 48, 816-827. doi:10.1055/s-0035-1561313

40. Mizar, P.; Niebuhr, R.; Hutchings, M.; Farooq, U.; Wirth, T. Chem. - Eur. J. 2016, 22, 1614-1617. doi:10.1002/chem.201504636

41. Brown, M.; Kumar, R.; Rehbein, J.; Wirth, T. Chem. - Eur. J. 2016, 22 , 4030-4035. doi:10.1002/chem.201504844

42. Shimogaki, M.; Fujita, M.; Sugimura, T. Angew. Chem., Int. Ed. 2016, 55, 15797-15801. doi:10.1002/anie.201609110 Angew. Chem. 2016, 128, 16029-16033. doi:10.1002/ange.201609110 43. Alhalib, A.; Kamouka, S.; Moran, W. J. Org. Lett. 2015, 17, 1453-1456. doi:10.1021/acs.orglett.5b00333

44. Takesue, T.; Fujita, M.; Sugimura, T.; Akutsu, H. Org. Lett. 2014, 16, 4634-4637. doi:10.1021/ol502225p 
45. Kong, W.; Feige, P.; de Haro, T.; Nevado, C. Angew. Chem., Int. Ed. 2013, 52, 2469-2473. doi:10.1002/anie.201208471

Angew. Chem. 2013, 125, 2529-2533. doi:10.1002/ange.201208471

46. Farid, U.; Malmedy, F.; Claveau, R.; Albers, L.; Wirth, T.

Angew. Chem., Int. Ed. 2013, 52, 7018-7022.

doi:10.1002/anie.201302358

Angew. Chem. 2013, 125, 7156-7160. doi:10.1002/ange.201302358

47. Fujita, M.; Mori, K.; Shimogaki, M.; Sugimura, T. RSC Adv. 2013, 3, 17717-17725. doi:10.1039/c3ra43230k

48. Farid, U.; Wirth, T. Angew. Chem., Int. Ed. 2012, 51, 3462-3465. doi:10.1002/anie.201107703

Angew. Chem. 2012, 124, 3518-3522. doi:10.1002/ange.201107703

49. Röben, C.; Souto, J. A.; González, Y.; Lishchynskyi, A.; Muñiz, K.

Angew. Chem., Int. Ed. 2011, 50, 9478-9482.

doi:10.1002/anie.201103077

Angew. Chem. 2011, 123, 9650-9654. doi:10.1002/ange.201103077

50. Fujita, M.; Wakita, M.; Sugimura, T. Chem. Commun. 2011, 47, 3983-3985. doi:10.1039/c1cc10129c

51. Koser, G. F.; Wettach, R. H. J. Org. Chem. 1977, 42, 1476-1478. doi:10.1021/jo00428a052

52. Koser, G. F.; Rebrovic, L.; Wettach, R. H. J. Org. Chem. 1981, 46, 4324-4326. doi:10.1021/jo00334a057

53. Rebrovic, L.; Koser, G. F. J. Org. Chem. 1984, 49, 2462-2472. doi:10.1021/jo00187a032

54. Okuyama, T.; Takino, T.; Sueda, T.; Ochiai, M. J. Am. Chem. Soc. 1995, 117, 3360-3367. doi:10.1021/ja00117a006

\section{License and Terms}

This is an Open Access article under the terms of the Creative Commons Attribution License (http://creativecommons.org/licenses/by/4.0), which permits unrestricted use, distribution, and reproduction in any medium, provided the original work is properly cited.

The license is subject to the Beilstein Journal of Organic Chemistry terms and conditions:

(https://www.beilstein-journals.org/bjoc)

The definitive version of this article is the electronic one which can be found at: doi:10.3762/bjoc. 14.53 